\title{
反応速度差法による無機化学種の酸化状態別分析
}

\author{
山田真吉**
}

\section{Differential kinetic methods for the determination of inorganic species in different oxidation states}

\author{
Shinkichi YAMADA ${ }^{* *}$ \\ ${ }^{* *}$ Faculty of Engineering, Shizuoka University, 3-5-1, Johoku, Hamamastu-shi, Shizuoka 432-8561
}

(Received 30 April 1998, Accepted 14 July 1998)

\begin{abstract}
From a mechanistic consideration of the reactivity of a metal ion and its complex, we have proposed equations to predict the rate constants for complex formation and ligandsubstitution reactions, as well as the catalytic effect of a third ligand on a ligand-substitution reaction. Using these equations and the parameters involved in these equations, we have designed differential kinetic methods for determining inorganic species in different oxidation states. These include (1) the simultaneous determination of antimony(III) and antimony $(\mathrm{V})$ based on the difference in rates for complexation with 3-hydroxy-7methoxyflavone, (2) the selective determination of antimony $(\mathrm{V})$ in the presence of antimony(III) based on the difference in rates for the ligand substitution of the 3-hydroxy-7methoxyflavone complex with citrate, (3) the selective determination of tin(IV) in the presence of tin(II) based on the difference in rates for the complexation with morin, and (4) the selective determination of thiosulfate and sulfite in the presence of sulfate based on the difference in rates for the catalytic effect on the ligand substitution of mercury(II)PAR complex with CyDTA.
\end{abstract}

Keywords : differential kinetic method of analysis; determination of antimony; determination of tin; determination of oxy-anions of sulfur.

\section{1 緒言}

反応系が平衡状態に至る過渡現象の差に着目した速度 差分析法には各種の反応が用いられている(1)-4が, 金属 錯体を金属指示薬で置換する反応は比較的多用される反 応の一つである。これは，化学的性質が異なる配位子を 適切に組み合わせることにより反応速度を容易に変えら れること, 反応溶液の $\mathrm{pH}$ を変化させるだけでも反応速 度を変えられること, 金属指示薬にアゾ色素あるいは蛍

* 中部支部創立 40 周年記念

** 静岡大学工学部: 432-8561 静岡県浜松市城北 3-5-1
光性有機試薬を選ぶと高感度定量が可能になることなど の理由による，配位子置換反応系を用いて提案された速 度差分析法はこれまでかなりの数に上るが, 反応系の選 択, 反応条件の最適化等については経験によるものが多 い. 配位子置換反応の全速度定数が律速段階前の平衡定 数と律速段階の速度定数の皘で表現される場合が多いこ とを考虑すると, 錯形成反応の熱力学と金属錯体の反応 性を統一的な考えの下に記述することが配位子置換反応 系を用いる速度差分析法の開発には不可欠となろう。こ のような観点から, 著者らは金属錯体の熱力学及び速度 論的性質を支配している要因を金属イオン及び配位子の 
性質との関連で理解, 记述じ1-11), この考え方を経験 に基づいて設䛨されてきた速度差分析法の解釈に応用す る(2) (14) とともに，新しい速度差分析法の開発に応用市

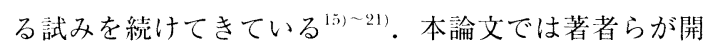
発した速度差分析法のうち, 酸化数の異なる元素の定量 に関するう法について, 印刷物として公表されていない 最近の成果も父えながら報告する.

\section{2 速度差分析法による定量の原理}

$\mathrm{M}$ と N という酸化数だけが異なる二つの金属イオン が金属指示薬（以下，陚薬と略称） $\mathrm{R}$ と同じ条件で反心 して錯体 MR 及びNR を生成する場合を例にして, 速度 差分析法による定量の代表的な手法を示す.

それぞれの錯体の生成速度定数を $k_{\mathrm{M}}$ 及び $k_{\mathrm{N}}$ とする と,この反応は

$$
\begin{aligned}
& \mathrm{M}+\mathrm{R} \stackrel{k_{\mathrm{M}}}{\rightarrow} \mathrm{MR} \\
& \mathrm{N}+\mathrm{R} \stackrel{k \mathrm{~s}}{\rightarrow} \mathrm{NR}
\end{aligned}
$$

と表される(化学種の電何は省略する)。両金属イオン の全濃度（それぞれ $C_{\mathrm{N}} ， C_{\mathrm{N}}$ で表す）に対して大過剩の 試薬（その全濃度を( C MRの生成速度式は

$$
\mathrm{d}[\mathrm{MR}] / \mathrm{d} t=k_{\mathrm{M}}[\mathrm{M}] C_{\mathrm{R}}
$$

で与えられる。この式を積分して, 反応開始 $t$ 秒後での 試薬と末反伈の M の濃度を求めると

$$
[\mathrm{M}]=C_{\mathrm{M}} \exp \left(-k_{\mathrm{M}} C_{\mathrm{R}} t\right)
$$

を得る、いま，Mと $\mathrm{N}$ とを含む溶液に R を加えたとす ると,この場令に観察される系全体の経時変化は

$$
[\mathrm{M}]+[\mathrm{N}]=C_{\mathrm{M}} \exp \left(-k_{\mathrm{M}} C_{\mathrm{R}} t\right)+C_{\mathrm{N}} \exp \left(-k_{\mathrm{N}} C_{\mathrm{R}} t\right)
$$

で表される， $k_{M}>k_{N}$ で式( 1 ) の反応だけが完結した後 では $\exp \left(-k_{\mathrm{M}} C_{\mathrm{R}} t\right)=0$ と近似できるので, このような場 合には式(5)は

$$
[\mathrm{N}]=C_{\mathrm{N}} \exp \left(-k_{\mathrm{N}} C_{\mathrm{R}} t\right)
$$

と書き換えられる，Rに対する $\mathrm{N}$ の応性が更に低く なると $\exp \left(-k_{\mathrm{N}} C_{\mathrm{R}} t\right)=1-k_{\mathrm{N}} C_{\mathrm{R}} t$ と近似できる反応時間带
が存在し得るので，このような場合には式（6）は

$$
[\mathrm{N}]=C_{\mathrm{N}}-C_{\mathrm{N}} k_{\mathrm{N}} C_{\mathrm{K}}
$$

と書き換えられる。従って，式（6）の近似が成り立つ

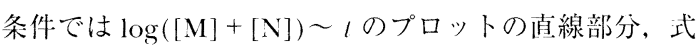
(7) の近似が成り立つ条件では $([\mathrm{M}]+[\mathrm{N}])$ 一 のプロ ットの直線部分を用い机ば，M共存下で $\mathrm{N} か ゙$ 選択定量

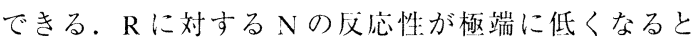
$\exp \left(-k_{\backslash} C_{\mathrm{R}} t\right)=1$ と近似できる反応時間带が存在し得る. このような場合には, 式 (4)で表される M の経時変化 だけが観測されるので，N共存下で Mが選択定量でき る.

ここで, 式（1）及び（2）の反㐫を吸光光度法で追 跡する場合を考える，R，MR及び NRのモル吸光係数 をそれぞれ $\varepsilon_{\mathrm{R}}, \varepsilon_{\mathrm{NR}}$ 及び $\varepsilon_{\mathrm{NR}}$ で表すと（M と $\mathrm{N}$ の吸収は 無視できるものとする), 反応開始 $t$ 秒後の吸光度 $A_{1}$ は

$$
\begin{aligned}
A_{\mathrm{t}}=\varepsilon_{\mathrm{R}} C_{\mathrm{R}}+\varepsilon_{\mathrm{MR}} C_{\mathrm{M} 1}\{1- & \left.\exp \left(-k_{\mathrm{M}} C_{\mathrm{R}} t\right)\right\} \\
& +\varepsilon_{\mathrm{NR}} C_{\mathrm{N}}\left\{1-\exp \left(-k_{\mathrm{N}} C_{\mathrm{R}} t\right)\right\}
\end{aligned}
$$

で与えられる。この式に式 (6) 及び（7）の近似をあ てはめると，それぞれ

$$
\begin{aligned}
& A_{\mathrm{t}}^{=}=\varepsilon_{\mathrm{R}} C_{\mathrm{R}}+\varepsilon_{\mathrm{NR}} C_{\mathrm{M}} \\
& \quad+\varepsilon_{\mathrm{NR}} C_{\mathrm{N}}\{1- \\
& A_{\mathrm{t}}=\varepsilon_{\mathrm{R}} C_{\mathrm{R}}+\varepsilon_{\mathrm{MR}} C_{\mathrm{M}}+\varepsilon_{\mathrm{NR}} C_{\mathrm{N}} k_{\mathrm{N}} C_{\mathrm{R}} l
\end{aligned}
$$

を得る、反応開始時及び反応完結後の吸光度を $A_{0}$ 及び $A_{\infty}$ で表すと

$$
\begin{aligned}
& A_{0}=\varepsilon_{\mathrm{R}} C_{\mathrm{R}} \\
& A_{\infty}=\varepsilon_{\mathrm{R}} C_{\mathrm{R}}+\varepsilon_{\mathrm{NR}} C_{\mathrm{N}}+\varepsilon_{\mathrm{NR}} C_{\mathrm{N}}
\end{aligned}
$$

となるので, 式(9)と（12）及び式(10)と（11）より

$$
\begin{aligned}
& A_{\infty}-A_{\mathrm{l}}=\varepsilon_{\mathrm{NR}} C_{\mathrm{N}} \exp \left(-k_{\mathrm{N}} C_{\mathrm{R}} t\right) \\
& A_{\mathrm{t}}-A_{0}=\varepsilon_{\mathrm{NR}} C_{\mathrm{M}}+\varepsilon_{\mathrm{NR}} C_{\mathrm{N}} k_{\mathrm{N}} C_{\mathrm{R}} t
\end{aligned}
$$

を得る. 式(13)より, $\log \left(A_{\infty}-A_{1}\right) \sim$ ののプロットの值 線部分の切片から $\mathrm{M}$ 共存下での Nが選択定量できる (logarithmic extrapolation method). 一方, 式(14)よ り, $\left(A_{t}-A_{0}\right) \sim t$ のプロットの直線部分の切片から $\mathrm{N}$ 共 存下での M が, 傾きから $\mathrm{M}$ 共存下での Nが選択定量 できる (linear extrapolation method). 又, 式( 9 )で 
特定の反応時間（ $t_{1}$ 及び $t_{2} ）$ での吸光度差 $\Delta A=A_{t 1}-A_{t 2}$ は

$$
\Delta A=\varepsilon_{\mathrm{NR}} C_{\mathrm{N}}\left\{\exp \left(-k_{\mathrm{N}} C_{\mathrm{R}} t_{2}\right)-\exp \left(-k_{\mathrm{N}} C_{\mathrm{R}} t_{1}\right)\right\}
$$

で表されるので，式(15）を用いても M 共存下での N が 選択定量できる。いずれにせよ，速度差分析法により特 定の化学種を選択定量あるいは複数の化学種を同時定量 するためには，それぞれの化学種間に式(4)，（6）あ るいは（7）のいずれかの近似が成立するような条件を 設定することが不可欠となる。このほかの手法について

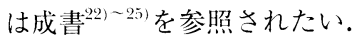

\section{3 速度差をもたらす反応系の設計 ${ }^{(2) ー 1+~}$}

金属錯体 MY と金属指示薬 $\mathrm{R}$ とから混合配位子錯体 YMR を生成する反応

$$
\begin{gathered}
K_{\mathrm{Os}(\mathrm{MY}, \mathrm{R})} \quad k_{\mathrm{MY}}{ }^{-\mathrm{H}_{2} \mathrm{O}} \\
k_{\mathrm{MYR}}{ }^{\mathrm{R}}
\end{gathered}
$$

において（電荷及び配位水分子を省略する），YMRから $\mathrm{R}$ が解離する速度定数 $k_{\mathrm{MMR}}{ }^{-\mathrm{R}}$ は，水分子を基準配位子 とすると

$$
\log \left(k_{\mathrm{YMR}}{ }^{-\mathrm{R}} / k_{\mathrm{M}}{ }^{-\mathrm{H}_{\mathrm{z}} \mathrm{O}}\right)=\gamma E(\mathrm{Y})-\alpha E(\mathrm{R})-\beta H(\mathrm{R})
$$

で表される ${ }^{26)}$.この式を用い, 錯形成反応及び配位子置 換反応の発色速度定数 $k_{\mathrm{f}}$ と退色速度定数 $k_{\mathrm{r}}$ がどのよう に記述されるのかを考察する。なお，式（16）の $K_{\mathrm{ns}(\mathrm{MY}, \mathrm{R})}$ は外圈錯体 $[\mathrm{MY}, \mathrm{R}]$ の生成定数, $k_{\mathrm{MYY}}{ }^{-\mathrm{H}_{\mathrm{2}} \mathrm{O}}$ は $\mathrm{MY}$ の配位水分子交換速度定数, $E$ 及び $H$ は括弧内に示し た配位子の電子供与定数及び塩基性定数であり， $\alpha, \beta$ 及び $\gamma$ は金属イオン $\mathrm{M}$ に固有の定数である（これらの 定数の定義及びその評価法については引用文献 参照されたい).

\section{$3 \cdot 1$ 錯形成反応}

錯形成反応は式 (16) で $\mathrm{Y}=\mathrm{H}_{2} \mathrm{O}$ の場合の右方向への 反応に相当するので, 錯形成に伴う発色反応の速度定数 $k_{f}$ は

$$
\log k_{\mathrm{f}}=\log K_{\circ \varsigma(\mathrm{M}, \mathrm{R})}+\log k_{\mathrm{M}}{ }^{-\mathrm{H}_{\mathrm{O}} \mathrm{O}}
$$

で与えられる. Table 1 の $\mathrm{Fe}^{3+} / \mathrm{Fe}^{2+}$ に見られるように，
酸化数により $k_{\mathrm{M}}{ }^{-\mathrm{H}} \mathrm{O}$ がかなり異なる金属イオンが比較 的多いので，錯形成反応は酸化数の異なる金属イオンの 速度差分析に利用できる。

\section{$3 \cdot 2$ 配位子置換反応}

この反応は式（16）で生成したYMRが反応中間体と なり，この中間体から Y が解離して発色錯体 MR を生 成する機構

$$
\mathrm{MY}+\mathrm{R} \rightleftarrows \mathrm{YMR} \rightleftarrows \mathrm{MR}+\mathrm{Y}
$$

で進行し，発色反応ではYMRの M-Y 結合の切断が，退 色反応では YMRの M-R 結合の切断が律速となる場合が 一般的である。ここで，MYにR が配位する平衡定数及 びMRにYが配位する平衡定数を $K_{\mathrm{YMR}}{ }^{\mathrm{R}}$ 及び $K_{\mathrm{YMR}}{ }^{\mathrm{Y}}$ で表 し, YMR から Y が解離する速度定数及び YMR から R が解離する速度定数を $k_{\mathrm{YMR}}{ }^{-\mathrm{Y}}$ 及び $k_{\mathrm{YMR}}{ }^{-\mathrm{R}}$ で表すと, 発 色反応の全速度定数 $k_{\mathrm{f}}$ と退色反応の全速度定数 $k_{\mathrm{r}}$ は, それぞれ

$$
\begin{aligned}
& k_{\mathrm{f}}=K_{\mathrm{YMR}}{ }^{\mathrm{R}} k_{\mathrm{YMR}}{ }^{-\mathrm{Y}} \\
& k_{\mathrm{r}}=K_{\mathrm{YMR}}{ }^{\mathrm{Y}} k_{\mathrm{YMR}}{ }^{-\mathrm{R}}
\end{aligned}
$$

で与えられる。式(20)の $K_{\mathrm{YMR}}{ }^{\mathrm{R}}$ は式(16)より

$$
K_{\mathrm{YMR}}{ }^{\mathrm{R}}=K_{\mathrm{os}(\mathrm{MY}, \mathrm{R})} k_{\mathrm{MY}}{ }^{-\mathrm{H}_{\mathrm{O}} \mathrm{O}} / k_{\mathrm{MR}}{ }^{-\mathrm{R}}
$$

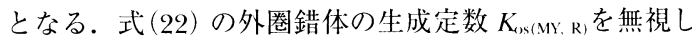
て式(20)を式(22) と（17）とを用いて書き換えると

$$
\begin{aligned}
\log k_{\mathrm{f}}=\alpha\{E(\mathrm{R})-E(\mathrm{Y})\}+ & \beta\{H(\mathrm{R})-H(\mathrm{Y})\} \\
& +\gamma E(\mathrm{R})+\log k_{\mathrm{M}}{ }^{-\mathrm{H}_{\mathrm{L}} \mathrm{O}}
\end{aligned}
$$

となる.式(21)についても同様な取り扱いより

$$
\begin{aligned}
\log k_{\mathrm{r}}=\alpha\{E(\mathrm{Y})-E(\mathrm{R})\}+ & \beta\{H(\mathrm{Y})-H(\mathrm{R})\} \\
& +\gamma E(\mathrm{Y})+\log k_{\mathrm{M}}{ }^{-\mathrm{H}_{\mathrm{O}} \mathrm{O}}
\end{aligned}
$$

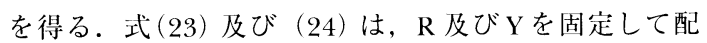
位子に固有のパラメーター $E$ と $H$ を一定にしても， $k_{\mathrm{f}}$ 及び $k_{\mathrm{r}}$ は金属イオンに固有のパラメーター $\alpha, \beta, \gamma$ 及 び $k_{\mathrm{M}}{ }^{-\mathrm{H}_{2} \mathrm{O}}$ を含み, $3 \cdot 1$ で述べたように $k_{\mathrm{M}}{ }^{-\mathrm{H}_{2} \mathrm{O}}$ は金属イ オンの酸化数によりかなり異なる場合が比較的多いの で, 配位子置換反応も酸化数の異なる金属イオンの速度 差分析に利用できる。 
ところで, 式 (19) の左方向への反応に, 触媒として 働く第 3 の配位子Aが共存すると

$$
\mathrm{MR} \stackrel{\mathrm{A}}{\rightleftarrows} \mathrm{MAR}+\mathrm{Y} \rightleftarrows \mathrm{YMAR} \rightleftarrows \mathrm{MY}+\mathrm{R}+\mathrm{A}
$$

という中間体 YMAR の生成を含む接触反応経路が生じ, その分だけ反応は速くなる。この接触反応経路に対する 全速度定数 $k_{\mathrm{r}}{ }^{\mathrm{A}}$ は，MRにA が配位する平衡定数及び MARにYが配位する平衡定数を $K_{\mathrm{VAR}}{ }^{\prime}$ 及び $K_{\mathrm{M} \mathrm{MAR}}{ }^{\mathrm{Y}}$ で表 L, YMAR から R と A が解離する速度定数を $k_{\mathrm{M} M \mathrm{NR}}{ }^{-\mathrm{R}}$ で 表すと.

$$
k_{r}{ }^{A}=K_{\mathrm{MAR}}{ }^{\lambda} K_{\mathrm{YMAR}}{ }^{\mathrm{Y}} k_{\mathrm{YMAR}}{ }^{-\mathrm{R}}
$$

となるので，上と同様な取り扱いから

$$
\log k_{\mathrm{r}}{ }^{1}=\log k_{\mathrm{r}}+\alpha E(\mathrm{~A})+\beta H(\mathrm{~A})+\gamma E(\mathrm{~A})
$$

を得る。すなわち，式(24)で記述される $\log k_{r}$ に比べ て $\log k_{r}{ }^{\prime}$ は $\alpha E(\mathrm{~A})+\beta H(\mathrm{~A})+\gamma E(\mathrm{~A})$ だけ, 言い替えれば $\log K_{\mathrm{MA}}+\gamma E(\mathrm{~A})$ だけ大きくなる。従って， $k_{r}{ }^{\prime}$ の值に $\mathrm{A}$ 間で両者を区別できる程度の差があれば，配位子置換反 応に及ぼす Aの接触効果は酸化数の異なる元素を含む Aの速度差分析に利用できる.

以上述べたように，錯形成反応を用いる場合は式 (18) で，配位子置換反応を用いる場合は式（23）あるいは （24）で，配位子置換反応への接触効果を用いる場合は 式（27）で速度差を考察することになる。この考察に必 要な金属イオンのパラメーターを Table 1 に, 配位子 のパラメーターを Table 2 に示す.なお, Table $10 \sigma$ は

$$
\sigma=\alpha /(\alpha+\beta)
$$

で定義されるパラメーターであり，これは金属イオンの 軟らかさの尺度となる ついては $\gamma$ 值, 次いで $\log k_{\mathrm{N}}^{-\mathrm{H}_{3} \mathrm{O}}$ 值の情報が不足してい るが，両方の值が得られている金属イオンについては

$$
\gamma=-3.6 \alpha+3.8
$$

\begin{tabular}{|c|c|c|c|c|c|}
\hline $\mathrm{M}^{n+}$ & $\alpha$ & $\beta$ & $\sigma$ & $\gamma$ & $\log k_{n}{ }^{-112 x}$ \\
\hline $\mathrm{Hg}^{2+}$ & 5.83 & -0.07 & 1.01 & & $\sim 9$ \\
\hline $\mathrm{Pd}^{2+}$ & 5.33 & -0.12 & 1.02 & & 2.7 \\
\hline $\mathrm{CH}_{3} \mathrm{Hg}^{+}$ & 4.21 & 0.11 & 0.97 & & \\
\hline $\mathrm{Cu}^{+}$ & 3.92 & 0.18 & 0.96 & & \\
\hline $\mathrm{Ag}^{+}$ & 3.60 & -0.09 & 1.03 & & \\
\hline $\mathrm{Cd}^{2+}$ & 1.66 & 0.07 & 0.96 & & $\sim 8.5$ \\
\hline $\mathrm{Cu}^{2+}$ & 1.64 & 0.21 & 0.89 & & 9.6 \\
\hline $\mathrm{Fe}^{3+}$ & 1.62 & 0.47 & 0.78 & 1.2 & 2.2 \\
\hline $\mathrm{In}^{3+}$ & 1.57 & 0.15 & 0.93 & & 4.6 \\
\hline $\mathrm{Zr}^{4+}$ & 1.45 & 1.10 & 0.57 & 0.70 & \\
\hline $\mathrm{Ni}^{2+}$ & 1.41 & 0.09 & 0.94 & 0.48 & 4.6 \\
\hline $\mathrm{Co}^{2+}$ & 1.39 & 0.12 & 0.92 & 0.47 & 6.4 \\
\hline $\mathrm{VO}^{2+}$ & 1.37 & 0.57 & 0.71 & 1.3 & $2.9^{a t} 9.0^{b)}$ \\
\hline $\mathrm{Sn}^{2+}$ & 1.35 & 0.50 & 0.73 & & \\
\hline $\mathrm{Cr}^{3+}$ & 1.29 & 0.68 & 0.65 & 2.2 & -5.6 \\
\hline $\mathrm{Zn}^{2+}$ & 1.25 & 0.13 & 0.91 & 0.30 & 7.5 \\
\hline $\mathrm{Tl}^{+}$ & 1.24 & 0.03 & 0.98 & & $\sim 4$ \\
\hline $\mathrm{Pb}^{2+}$ & 1.21 & 0.22 & 0.85 & & $\sim 9$ \\
\hline $\mathrm{Hf}^{1+}$ & 1.19 & 0.93 & 0.56 & 0.74 & \\
\hline $\mathrm{Fe}^{2+}$ & 1.13 & 0.21 & 0.84 & & 6.6 \\
\hline $\mathrm{Mn}^{2+}$ & 1.04 & 0.23 & 0.82 & & 7.5 \\
\hline $\mathrm{Ga}^{3+}$ & 1.01 & 0.73 & 0.58 & 1.1 & 2.6 \\
\hline $\mathrm{UO}_{2}{ }^{2+}$ & 0.95 & 0.58 & 0.62 & & \\
\hline $\mathrm{Bi}^{3+}$ & 0.89 & 0.13 & 0.87 & & \\
\hline $\mathrm{Ce}^{3+}$ & 0.79 & 0.48 & 0.62 & & $\sim 8$ \\
\hline $\mathrm{U}^{++}$ & 0.67 & 1.01 & 0.40 & & $2 \sim 3$ \\
\hline
\end{tabular}

で近似できる相関が見られるので，式(29)を用いれば Table 1 に示した金属イオンについては $\gamma$ の概略值が推 定できる，多座配位子に対するパラメーターも不足して
Table 1 Parameters for metal ion

a) for $\mathrm{H}_{2} \mathrm{O}$ in an axial position. b) for $\mathrm{H}_{2} \mathrm{O}$ in an equatorial position

Table 2 Parameters for ligand

\begin{tabular}{lcc}
\hline $\mathrm{L}^{\prime \prime}$ & $H(\mathrm{~L})$ & $E(\mathrm{~L})$ \\
\hline $\mathrm{H}_{2} \mathrm{O}$ & 0.00 & 0.00 \\
$\mathrm{NO}_{3}{ }^{-}$ & 0.32 & 0.29 \\
$\mathrm{SO}_{4}{ }^{2-}$ & 3.71 & 0.59 \\
$\mathrm{ClCH}_{3} \mathrm{COO}^{-}$ & 5.0 & 0.79 \\
$\mathrm{CH}_{3} \mathrm{COO}^{-}$ & 6.50 & 0.96 \\
$\mathrm{C}_{5} \mathrm{H}_{5} \mathrm{~N}$ & 6.96 & 1.20 \\
$\mathrm{C}_{6} \mathrm{H}_{5} \mathrm{O}^{-}$ & 11.79 & 1.46 \\
$\mathrm{~N}_{3}{ }^{-}$ & 6.4 & 1.58 \\
$\mathrm{NO}_{2}{ }^{-}$ & 4.89 & 1.73 \\
$\mathrm{C}_{6} \mathrm{H}_{5} \mathrm{NH}_{2}$ & 6.33 & 1.78 \\
$\mathrm{~S}_{2} \mathrm{O}_{3}{ }^{2-}$ & 3.32 & 2.52 \\
$\mathrm{SO}_{3}{ }^{2-}$ & 8.96 & 2.57 \\
$\left(\mathrm{NH}_{2}\right)_{2} \mathrm{CS}$ & 3.77 & 2.18 \\
$\mathrm{~F}^{-}$ & 4.93 & -0.27 \\
$\mathrm{Cl}^{-}$ & -5.3 & 1.24 \\
$\mathrm{Br}^{-}$ & -7.3 & 1.51 \\
$\mathrm{I}^{-}$ & -8.3 & 2.06 \\
$\mathrm{SCN}^{-}$ & 0.42 & 1.83 \\
$\mathrm{NH}_{3}$ & 10.98 & 1.84 \\
\hline
\end{tabular}


Table 3 Fluorescent characteristics of antimony complexes with 3-hydroxy-7-methoxyflavone

\begin{tabular}{|c|c|c|c|c|c|}
\hline & \multirow{2}{*}{$C_{12 S(0)} / \mathrm{M}$} & \multirow{2}{*}{$\lambda_{\mathrm{a}} / \mathrm{nm}$} & \multirow{2}{*}{$\lambda_{\mathrm{c} m} / \mathrm{nm}$} & \multicolumn{2}{|c|}{ F.I. } \\
\hline & & & & Complex & Reagent \\
\hline $\mathrm{Sb}$ (III) & 3 & 400 & 457 & 23.0 & 34.5 \\
\hline $\mathrm{Sb}(\mathrm{V})$ & 0.03 & 402 & 450 & 100.0 & 0.5 \\
\hline
\end{tabular}

$C_{\mathrm{sb}}=4 \times 10^{-7} \mathrm{M}, \mathrm{C}_{\mathrm{l}}=1 \times 10^{-1} \mathrm{M}$. a) Relative to the $\mathrm{Sb}(\mathrm{V})$ complex

いるが,ポリアミン及びアミノポリカルボン酸について は $E(\mathrm{~L})$ 值の推定法が提案されている゙．

$$
4 \text { アンチモンの定量 }
$$

\section{$4 \cdot 1$ 錯形成速度差を用いる方法}

著者らの研究公で微量金属イオンの蛍光缹量用試薬と して開発した幾つかの3-ヒドロキシフラボン誘導体 ${ }^{2 x_{1}} に$ ついて,アンチモンとの蛍光反応を検討した結果，雨ア ンチモンと酸性で反応して強い蛍光を発する錯体を生成 する3-ヒドロキシ-7-メトキシフラボンを試薬に選んだ。 酸については, 硫酸, 塩酸及び過塩素酸について検討し た結果, 硫酸酸性の条件が最も再現性が良く, 生成する 錯体の蛍光も強かったので硫酸を用いることとした。な お, 試薬の水への溶解度を考虑して, 反応溶液には最終 濃度が $50 \% \mathrm{v} / \mathrm{v}$ となるようにメタノールを添加した。又, すべての測定は循環恒温水槽及び恒温セルホルダーを用 い25ำで行った.

$4 \cdot 1 \cdot 1$ 錯形成平衡 最適試薬濃度 $\left(1 \times 10^{-4} \mathrm{M}\right)$ で，最大蛍光を発する錯体を生成する条件と錯体の励起 極大波長 $\left(\lambda_{\mathrm{cx}}\right)$ 及び蛍光極大波長 $\left(\lambda_{\mathrm{rm}}\right)$ を Table 3 に 示す。両アンチモン錯体の $\lambda_{\mathrm{cx}}$ 及び $\lambda_{\mathrm{em}}$ にはほとんど差 が見られなかったが, 最適硫酸濃度には顕著な差が見ら れた. $\mathrm{Sb}(\mathrm{III})$ 錯体の蛍光は硫酸濃度の増大とともに強 くなり，3〜 4 M で最大かつ一定となった。これに対し て, $\mathrm{Sb}(\mathrm{V})$ 錯体の蛍光は硫酸濃度が低いほど強くなり, $0.01 \mathrm{M}$ 程度で最大かつ一定となった。 それぞれの最適 硫酸濃度で生成する錯体の蛍光強度（F.I.）は $\mathrm{Sb}(\mathrm{V})$ の ほうが約 4 倍大きい。これらの結果は, Sb(III) の選択 定量には高濃度硫酸酸性が, $\mathrm{Sb}(\mathrm{V})$ の選択定量には低濃 度硫酸酸性が, 両アンチモンの同時定量には $\mathrm{Sb}(\mathrm{III})$ の 選択定量にかなり近い硫酸酸性が望ましい条件となるこ とを示している.

$4 \cdot 1 \cdot 2$ 錯形成速度 $\quad S b(I I I)$ についてはストップト フロー法, $\mathrm{Sb}(\mathrm{V})$ についてはサンプル混合装置（デッド タイム約 4 秒）を用いる二液混合法で求めた両錯体の 生成反応に対する擬一次の条件速度定数 $\left\{k_{\mathrm{f}(\mathrm{obs})}\right\}$ への硫

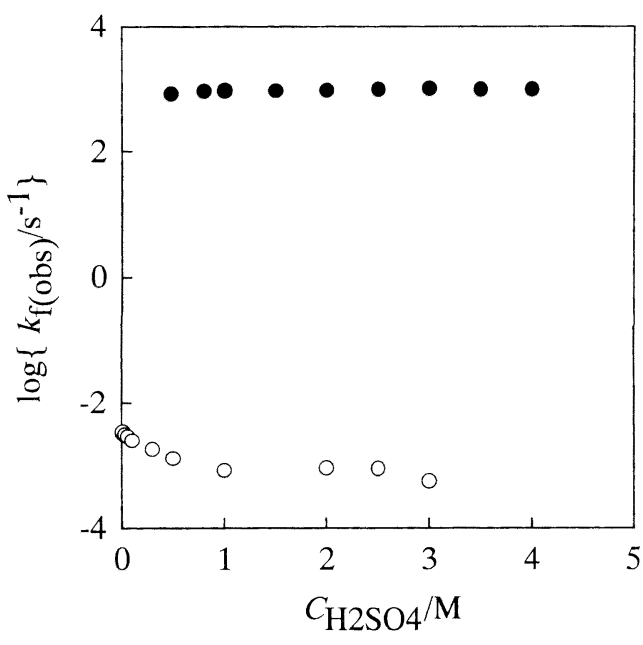

Fig. 1 Effect of sulfuric acid concentration on the rate constant for the formation of antimony(III) and antimony $(\mathrm{V})$ complexes with 3-hydroxy-7-methoxyflavone

$\mathrm{Sb}(\mathrm{III})(\mathrm{O}), \mathrm{Sb}(\mathrm{V})(\bigcirc): 4 \times 10^{-6} \mathrm{M}$; Reagent: $1 \times$ $10^{-4} \mathrm{M}$; Methanol: $50 \% \mathrm{w} / \mathrm{v}$

酸濃度依存性を Fig. 1 に示す. Sb (III) の反㐫は硫酸濃 度には依存しない, かなり速い反応であった（反応半減 期 $t_{1}$. は約 1 ミリ秒)。一方, $\mathrm{Sb}(\mathrm{V})$ の反忘は硫酸 $1 \sim 3$ $\mathrm{M}$ では硫酸濃度には依存しないが ( $t_{1 / 2}$ は約 20 分)，こ れより硫酸濃度が低下するにつれて反応はわずかに速く なり，0.01 M 程度で再び硫酸濃度依存性を示さなくな った ( $t_{1 / 2}$ は約 5 分).すなわち, Fig. 1 の硫酸酸性では 両アンチモンの反応性には5〜6けたの差があり,これ は式（７）の近似を成り立たせるに十分な差である。こ の差には両アンチモンの $k_{M}{ }^{-{ }_{2} O}$ の差 $\{$ 式(18) 参照\}が大 きく寄与していると予想される.

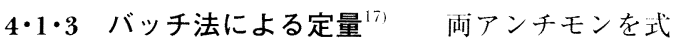
（7）に基づき分別定量するためには，それぞれの反心 が独立に進行することが前提となる．Fig．2に，文応曲 線の一例を示す。 $\mathrm{Sb}(\mathrm{III})$ 及び $\mathrm{Sb}(\mathrm{V})$ の) $k_{\mathrm{f}(\mathrm{obs})}$ をそれぞれ 


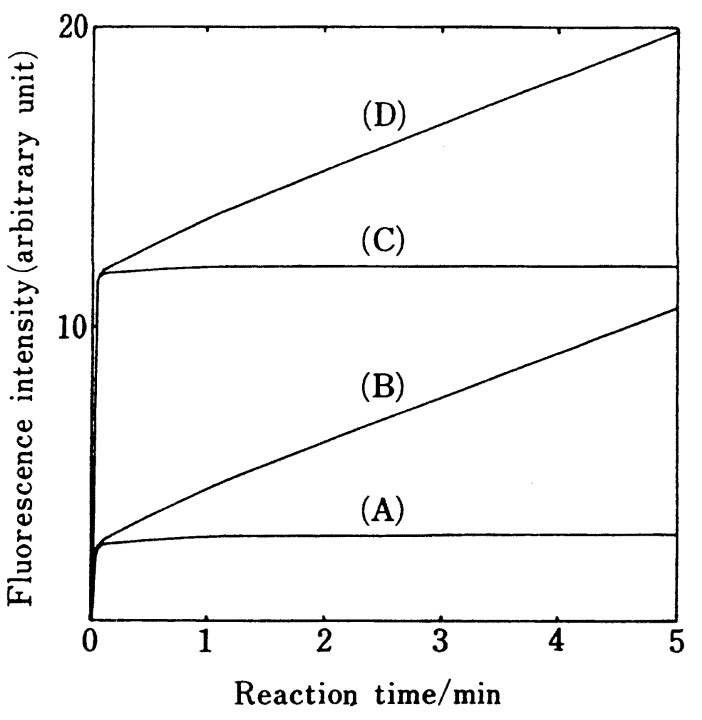

Fig. 2 Reaction curves for the formation of antimony(III) and antimony(V) complexes with 3hydroxy-7-methoxyflavone ${ }^{\text {i7) }}$

Reagent: $1 \times 10^{-4} \mathrm{M} ; \mathrm{H}_{2} \mathrm{SO}_{4}: 1 \mathrm{M}$; Methanol: $50 \%$ v/v; Sb: absence (A); $4 \times 10^{-7} \mathrm{M} \mathrm{Sb}(\mathrm{V})(\mathrm{B}) ; 4 \times$ $10^{-7} \mathrm{M} \mathrm{Sb}(\mathrm{III})(\mathrm{C}) ; 4 \times 10^{-7} \mathrm{M} \mathrm{Sb}(\mathrm{III})$ and $4 \times 10^{-7}$ $\mathrm{M} \mathrm{Sb}(\mathrm{V})(\mathrm{D})$

$k_{\mathrm{Sb}(\mathrm{III})}$ 及び $k_{\mathrm{Sb}(\mathrm{V})}$ で表すと, Fig. 2 の時間带では $\exp (-$ $\left.k_{\mathrm{Sb}(\mathrm{III})} t\right)=0, \exp \left(-k_{\mathrm{Sb}(\mathrm{V})} t\right)=1-k_{\mathrm{Sb}(\mathrm{V})} t$ と近似できる.す なわち, 式 $(8)$ の $A$ を蛍光強度 $(F)$ で読み替えると, Fig. 2 の（B）及び（C）はそれぞれ

$$
\begin{aligned}
& F_{\mathrm{t}}=f_{\mathrm{R}} C_{\mathrm{R}}+f_{\mathrm{sh}(\mathrm{V})} C_{\mathrm{Sb}(\mathrm{V})} k_{\mathrm{sb}(\mathrm{V})} t \\
& F_{\mathrm{t}}=f_{\mathrm{R}} C_{\mathrm{R}}+f_{\mathrm{sb}(\mathrm{III})} C_{\mathrm{Sb}(\mathrm{III})}
\end{aligned}
$$

で表される。なお， $f_{\mathrm{R}}, f_{\mathrm{Sb}(I I I)}$ 及び $f_{\mathrm{Sb}(\mathrm{V})}$ は試薬， $\mathrm{Sb}(\mathrm{III})$ 錯体及び $\mathrm{Sb}(\mathrm{V})$ 錯体 $1 \mathrm{M}$ 当たりの蛍光強度を示す。こ こで，両アンチモンが共存する場合の反応曲線（D）が $\mathrm{Sb}(\mathrm{V})$ 単独の場合の反応曲線（B）と平行移動の関係に あり，（D）の反応時間ゼロへの直線補外值が $\mathrm{Sb}(\mathrm{III})$ 錯 体の蛍光強度（C）に一致することは，Fig. 2の（D） が

$$
F_{\mathrm{t}}=f_{\mathrm{R}} C_{\mathrm{R}}+f_{\mathrm{sb}(\mathrm{HII})} C_{\mathrm{sb}(\mathrm{III})}+f_{\mathrm{sb}(\mathrm{V})} C_{\mathrm{sb}(\mathrm{V})} k_{\mathrm{Sb}(\mathrm{V})} t
$$

で表されることを示している，すなわち，本反応系で錯 形成以外の反応が進行するとしても，それらは Fig. 2 の反応時間内では無視できる.
（1） Sb(III) の選択定量硫酸 $3 \mathrm{M}$ で $\mathrm{Sb}$ (III) 溶液 と試薬溶液（最終濃度： $1 \times 10^{-4} \mathrm{M}$ ）とをサンプル混合 器で体積比 1:1 で混合し，457 nm での蛍光強度（励 起波長： $400 \mathrm{~nm}$ ）を約 2 分間測定し，蛍光強度の一定 值から $\mathrm{Sb}(\mathrm{III})$ を定量した。この方法により，検出限界 $7 \times 10^{-9} \mathrm{M}$ で $1 \times 10^{-6} \mathrm{M}$ までの $\mathrm{Sb}(\mathrm{III})$ が定量でき， $4 \times$ $10^{-7} \mathrm{M}$ の $\mathrm{Sb}(\mathrm{III})$ の定量において 125 倍モルまでの $\mathrm{Sb}(\mathrm{V})$ の共存が許容できた。なお，本法による $\mathrm{Sb}(\mathrm{III})$ の定量に及ぼす異種イオンの影響を検討したところ， Cr(VI) の共存許容量が極めて低いことが分かったので, 本反応系を微量 $\mathrm{Cr}(\mathrm{VI})$ の蛍光定量に応用した。その結 果, 検出限界 $4 \times 10^{-9} \mathrm{M}$ で $3.2 \times 10^{-6} \mathrm{M}$ までの $\operatorname{Cr}(\mathrm{VI})$ が定量でき， $2 \times 10^{-7} \mathrm{M}$ の $\mathrm{Cr}(\mathrm{VI})$ の定量において 1400 倍モルまでの $\operatorname{Cr}\left(\right.$ III) の共存が許容できた ${ }^{29)}$.

（2） $\mathbf{S b}(\mathbf{V})$ の選択定量 硫酸 $0.03 \mathrm{M}$ で $\mathrm{Sb}(\mathrm{V})$ 溶液 と試薬溶液（最終濃度： $1 \times 10^{-4} \mathrm{M} ）$ とを体積比 $1: 1$ て 混合し, $450 \mathrm{~nm}$ での蛍光強度（励起波長： $402 \mathrm{~nm}$ ）を 約 10 分間測定し, 反応開始 5 分後と 1 分後の蛍光強度 差から Sb(V) を定量した。この方法により，検出限界 $1.5 \times 10^{-8} \mathrm{M}$ で $1 \times 10^{-6} \mathrm{M}$ までの $\mathrm{Sb}(\mathrm{V})$ が定量でき， $4 \times 10^{-7} \mathrm{M}$ の $\mathrm{Sb}(\mathrm{V})$ の定量において 150 倍モルまでの $\mathrm{Sb}$ (III) の共存が許容できた.

（3）両アンチモンの同時定量 硫酸 $1 \mathrm{M}$ で両アン チモンを含む溶液と試薬溶液（最終濃度： $1 \times 10^{-4} \mathrm{M}$ ) とを体積比 $1: 1$ で混合し，454 nm での蛍光強度（励

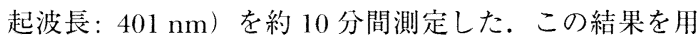
い, $4 \cdot 1 \cdot 3 \cdot 1$ 及び $4 \cdot 1 \cdot 3 \cdot 2$ で述べた方法で作成したそれ ぞれの検量線から，両アンチモンを定量した。両アンチ モンの和が $1 \times 10^{-6} \mathrm{M}$ となる溶液と同量の各アンチモ ンを $0 \sim 1 \times 10^{-6} \mathrm{M}$ 含む溶液 12 種類について検討した ところ，平均回収率 $106 \%$ で雨アンチモンが同時定量 できた.

4・1・4 FIA による定量 ${ }^{27} \quad 4 \cdot 1 \cdot 3$ に示したバッチ 法による結果を基に，蛍光検出 FIAによるアンチモン の分別定量を検討した.

（1） Sb(III) の選択定量 $\mathrm{Sb}$ (III) の選択定量条件と しては，4・1・1 で述べたように高濃度硫酸酸性が，反応 の遅い $\mathrm{Sb}(\mathrm{V})$ による影響を抑制するためには流路を短 くし流量を大きくするのが望ましい条件となる。これら を踏まえて種々検討した結果，反応コイルは用いず， $2 \times 10^{-4} \mathrm{M}$ の試薬を含む $1.5 \mathrm{M}$ 硫酸と $1.5 \mathrm{M}$ 硫酸キャリ ヤー溶液とを $1.8 \mathrm{ml} / \mathrm{min}$ で流し, キャリヤー側の流路 に Sb(III) を含む $1.5 \mathrm{M}$ 硫酸 $200 \mu \mathrm{l}$ を注入することとし

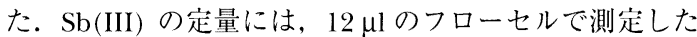
$460 \mathrm{~nm}$ での蛍光ピーク（励起波長: $398 \mathrm{~nm}$ ）を用いた. 
この方法により，検出限界 $3 \times 10^{-8} \mathrm{M} て ゙ ら \times 10^{-6} \mathrm{M}$ ま での $\mathrm{Sb}$ (III) が定量でき， $5 \times 10^{-7} \mathrm{M}$ の Sb(III) の定量に おいて 5 倍モルまでの $\mathrm{Sb}(\mathrm{V})$ の其存が許容できた $(20$ 〜30 サンプル $/ \mathrm{h}$ ).

（2） $\mathrm{Sb}(\mathrm{V})$ の選択定量 $\mathrm{Sb}(\mathrm{V})$ の選択定量条件とし ては，4・1・1で述べたように低濃度硫酸酸性が， $\mathrm{Sb}(\mathrm{V})$ 錯体の生成反応がかなり漣いことを考虑すると十分な反 応時間をとるのが望ましい条件となる，又，反応の速い $\mathrm{Sb}$ (III) による影響を除くためには，反応開始・定時間 後の蛍光強度差を用いる必要がある。こ机らを踏まえて 種々検討した結果, $\mathrm{Sb}(\mathrm{V})$ の定量にはストップトフロー

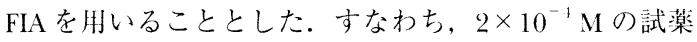
を含む $0.03 \mathrm{M}$ 硫酸と $0.03 \mathrm{M}$ 硫酸キャリヤ一溶液とを $1.8 \mathrm{ml} / \mathrm{min}$ で流し, キャリヤー側の流路に $\mathrm{Sb}(\mathrm{V})$ を含 む $0.03 \mathrm{M}$ 硫酸 $200 \mu \mathrm{l}$ を注入した。文応溶液がフローセ ルに到達した時点で流路を停止させ，451 nm での蛍光 ピーク（励起波長：402 nm) の経時变化を測定し $\mathrm{Sb}(\mathrm{V})$ を定量した。流路停止時と 3 分後の蛍光強度差と 流路停止 30 秒後と 5 分後の蛍光強度差とを組み合わせ

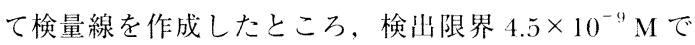
$1 \times 10^{-6} \mathrm{M}$ までの $\mathrm{Sb}(\mathrm{V})$ が定量でき， $2 \times 10^{-7} \mathrm{M} の$ $\mathrm{Sb}(\mathrm{V})$ の定量において5倍モルまでの $\mathrm{Sb}(\mathrm{III})$ の共有が 許容できた $(10$ サンプル/h).

（3）両アンチモンの同時定量両アンチモンの同 時定量には, 流量 $2.0 \mathrm{ml} / \mathrm{min}$ で, 長知“流路を用いて 反応時間差を設ける方法を用いた。すなわち，流路中に 切り替えバルブを接続し, 反忘コイルを経由しない短流 路で得られる蛍光ピークから反応の速い $\mathrm{Sb}$ (III) を定量 した後， $20 \mathrm{~m}$ の反忍コイルを経由する長流路で得られ るピークに対して Sb(III) の寄与を補正して反応の遅い $\mathrm{Sb}(\mathrm{V})$ を定量した。なお，硫酸濃度は $4 \cdot 1 \cdot 1$ で述べた理 由から $1 \mathrm{M}$ とした。 又, 測定波長には $\mathrm{Sb}(\mathrm{V})$ 錯体の励 起及び蛍光極大波長である 402 及び $451 \mathrm{~nm}$ を用いた。 この方法に従い作成したそれぞれの検量線を用い，画ア ンチモンの和が $8 \times 10^{-6} \mathrm{M}$ となる溶液 3 種類について 検討したところ，いずれについても $5 \%$ 以内の誤差で両 アンチモンが同時定量できた $(20 \sim 30$ サンプル $/ \mathrm{h})$.

\section{$4 \cdot 2$ 配位子置換速度差を用いる方法}

両アンチモンの3-ヒドロキシ-7-メトキシフラボン錯 体を置換試薬で配位子置換する反応を検討した。 $\mathrm{Sb}(\mathrm{III})$ 及び $\mathrm{Sb}(\mathrm{V})$ 錯体の蛍光強度は $459 \mathrm{~nm}$ (励起波

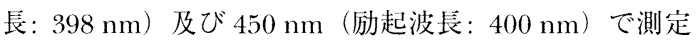
し, 反応溶液の酸性度は硫酸で調節した。置換剤として シュウ酸, 酒石酸, クエン酸, イミノ二酢酸（IDA）,
ニトリロ三酶酸（NTA），エチレンジアミン $N, N-\cdots$ 酹酸 (EDDA)，エチレンジアミン陌醉酸（EDTA），グリコー ルエーテルジアミン四酷酸 (GEDTA)，1,2-シクロヘキ サンジアミン $N, N, N, N$ 四酢酸（CyDTA）及びジエチレ ントリアミン五䣫酸（DTPA）を用いた。术忍溶液には 最終濃度が $50 \%$ v/v となるようにメタノールを添加し， すべての測定は $25^{\circ} \mathrm{C} て ゙$ でった。

$4 \cdot 2 \cdot 1$ 配位子置換反応 $\mathrm{Sb}(\mathrm{V})$ 錯体の反忍を硫酸 0.01〜1 M で追跡したところ, アミノポリカルボン酸を 用いた場合には飽和溶解度付近の濃度でも艾応は全く進

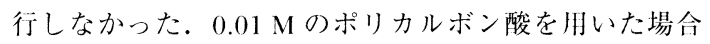

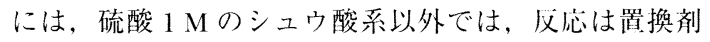
の種類と硫酸濃度には依存せず半減期45 分程度でほほ 定量的に進行した。 $50 \% \mathrm{v} / \mathrm{v}$ メタールへの溶解度の大 きい酒不酸とクエン酸について更に検討した絬果，(1) $\mathrm{Sb}(\mathrm{III})$ 錯体の反応はいず机の条件でも反応開始直後に 完結する，(2） $\mathrm{Sb}(\mathrm{V})$ 錯体の反忘はいずれの硫酸濃度で もクエン酸系のほうが逑い，(3) $\mathrm{Sb}(\mathrm{V})$ 錯体の反応の $F_{0}-F_{\infty}$ はクエン酸系と酒石酸系とでは大差ないことが分 かったので, $\mathrm{Sb}(\mathrm{V})$ の定量のための置換剂としてクエン 酸を選んだ．この配位子置換反忘の全速度定数は式(24) で記述される（Yがクエン酸, R が 3-ヒドロキシ-7-メト キシフラボンに相当する). $4 \cdot 1 \cdot 2$ で予想したと问様に,

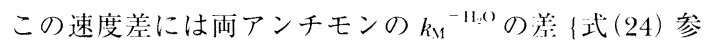
照\}が大きく寄与していると予想される.

$4 \cdot 2 \cdot 2 \mathrm{Sb}(\mathrm{V})$ の選択定量 硫酸 $0.1 \mathrm{M}$ で $\mathrm{Sb}(\mathrm{V})$ と 試薬（最終濃度： $1 \times 10^{-4} \mathrm{M}$ ）とを会む溶液とクエン酸 （最終濃度：0.1 M）溶液とを体積比 $1: 1$ で混令し, 450 $\mathrm{nm}$ での蛍光強度 (励起波長: $400 \mathrm{~nm}$ ) で約 45 分閒測 定し, 反応開始 5 分後と 30 分後の蛍光強度差から $\mathrm{Sb}(\mathrm{V})$ を定量した。この方法により, 検出限界 $8 \times 10^{-9}$ $\mathrm{M}$ で $1 \times 10^{-6} \mathrm{M}$ までの $\mathrm{Sb}(\mathrm{V})$ が定量でき, $4 \times 10^{-7} \mathrm{M}$ の $\mathrm{Sb}(\mathrm{V})$ の定量において 50 倍モルまでの $\mathrm{Sb}(\mathrm{III})$ の共 存が許容できた.

\section{5 スズの定量 ${ }^{200}$}

錯形成速度の差が酸化数の買なる金属イオンの分別定 量に有効であることをアンチモンについてホすことがで きたので，この差を用いるスズの分別定量を検討した。 試薬としてはSn(II) 及びSn(IV) のいずれとも酸性で反 応して強い蛍光を発する錯体を生成するモリンを選ん だ.酸については塩酸及びリン酸中では蛍光性錯体の生 成はほとんど認められなかったが, 硫酸及び過塩素酸中 では比較的強い蛍光を発する錯体の生成が認められたの で、これらの酸中での反応を検討した。なお，スズの速 
Table 4 Fluorescent characteristics of tin complexes with morin

\begin{tabular}{|c|c|c|c|c|c|}
\hline & \multirow{2}{*}{ (alesot $/ \mathrm{M}$} & \multirow{2}{*}{$\lambda_{\mathrm{r} \cdot \mathrm{x}} / \mathrm{nm}$} & \multirow{2}{*}{$\lambda_{\mathrm{em}} / \mathrm{nm}$} & \multicolumn{2}{|c|}{ F.I." } \\
\hline & & & & Complex & Reagent \\
\hline $\operatorname{Sn}(\mathrm{II})$ & 1.5 & 435 & 500 & 100.0 & 1.4 \\
\hline $\operatorname{Sn}(I V)$ & 1.5 & 435 & 500 & 94.0 & 1.4 \\
\hline
\end{tabular}

$C_{S 11}=1 \times 10^{-5} \mathrm{M}, C_{1}=8 \times 10^{-4} \mathrm{M}$. a) Relative to the Sn(II) complex

度差分析に古接に関倸する両スズ錯体の生成速度差は過 塩素酸中より硫酸中のほうが大きかったので，ここでは 硫酸中での結果だけを示す。又, アンチモンの場合と同 様に, 反溶液には最終濃度が $50 \% \mathrm{v} / \mathrm{v}$ となるように

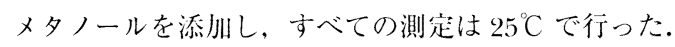

\section{$5 \cdot 1$ 錯形成反応}

最適弐楽濃度 $\left(8 \times 10^{-4} \mathrm{M}\right)$ で, 最大蛍光を発する錯 体を生成する条件と錯体の $\lambda_{\mathrm{rx}}$ 及び $\lambda_{\mathrm{em}}$ を Table 4 に示 す. $\lambda_{\mathrm{cx}}, \lambda_{\mathrm{cm}}$, 最適硫酸濃度及びそれぞれの最適条件で 生成する錯体の蛍光強度いずれについても両スズ錯体間 ではほとんど美が見られなかった。サンプル混合装置を 用いる。液混合法で求めた両スズ錯体の生成反応に対す

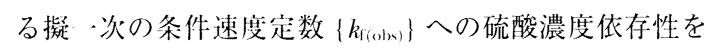
Fig. 3 に亦す。硫酸 $1 \mathrm{M}$ 以上では 50 倍以上の速度差が あり，反心開始 5 秒以降では式 (6) の近似が成り立つ ことが分かる.この差には, アンチモンの場合と同様に, 屾スズの $k_{M}^{-1100}$ の差 $\{$ 式(18) 参照\}が大きく寄与してい るとア想される。なお，上述の Sn(II) の反応は Sn(II) の空父酸化を防ぐため還元剂（チオグリコール酸）を添 加して行ったので, Fig. 2に示したような検討をスズの 場命には行うことができなかった。しかし，Sn(IV) を 部分還元した活スズ混合系での反応曲線の速度解析と $F_{\infty}$ の值は, 速度論的にも熱力学的にも両スズの反応が 独泣に洋行して進行していることを示唆している.

\section{$5 \cdot 2 \mathrm{Sn}(\mathrm{IV})$ の選択定量}

硫酸 $1.5 \mathrm{M}$ で $\mathrm{Sn}(\mathrm{IV})$ 溶液と試薬溶液（最終濃度: $8 \times$ $\left.10^{-4} \mathrm{M}\right)$ とを体積比 $1: 1$ で混合し, $500 \mathrm{~nm}$ での蛍光 強度（励起波長： $435 \mathrm{~nm}$ ) を約 2 分間測定し, 反応開 始 20 秒後と 1 分後の蛍光強度差から Sn (IV) を定量し た。この方法により，検出限界 $2 \times 10^{-7} \mathrm{M} て ゙ 1 \times 10^{-5} \mathrm{M}$ までの Sn(IV) が定量できた。なお，5・1で述べた理由 で, 本法を用いる Sn(IV) の定量に対するSn(II) の共存 詐欲量は直接には評価できなかった。しかし，本法を利 用したチオグリコール酸による $\mathrm{Sn}(\mathrm{IV})$ の還元反応機構

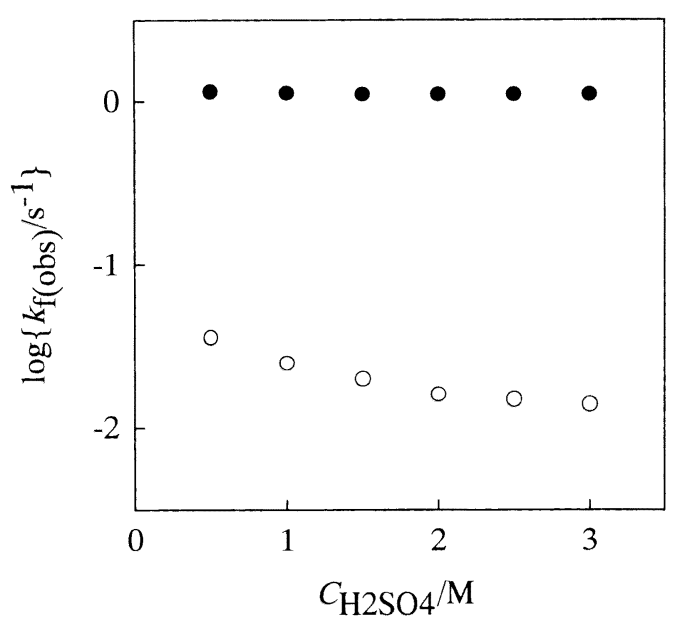

Fig. 3 Effect of sulfuric acid concentration on the rate constant for the formation of tin(II) and tin(IV) complexes with morin

$\mathrm{Sn}(\mathrm{II})(\mathrm{O}), \mathrm{Sn}(\mathrm{IV})(\bigcirc): 1 \times 10^{-5} \mathrm{M}$; Reagent: $8 \times$ $10^{-4} \mathrm{M}$; Methanol: $50 \% \mathrm{v} / \mathrm{v}$

の検討結果 ${ }^{311}$ は, $2 \mathrm{M}$ 過塭素酸中での $10^{-6} \mathrm{M}$ オーダー の Sn(IV)の定量に対して7倍モルまでのSn(II) の共存 が許容できることを示している.

\section{6 硫黄の定量 ${ }^{21}$}

$3 \cdot 2$ で述べたように, 式(19)の左方向への反応に触 媒として働く第 3 の配位子 A は, 式(27) で表される加 速効果を示す. $\mathrm{M}$ が $\mathrm{Hg}^{2+}$ の場合には, Table 1 の $\mathrm{Hg}^{2+}$ の $\sigma$ 值と式(29) とから $\mathrm{Hg}^{2+}$ の $\gamma$ はゼロに近い值 と推定されるので, 式(27)は

$$
\log \left(k_{r}{ }^{A} / k_{r}\right)=\alpha E(\mathrm{~A})+\beta H(\mathrm{~A})=\log K_{\mathrm{Hg} \cdot 1}
$$

と近似できる. 更に, Table 1 の $\mathrm{Hg}^{2+}$ の $\alpha$ 及び $\beta$ 值か ら, かなりの Aについて $\alpha E(\mathrm{~A})>\beta H(\mathrm{~A})$ が成り立つと 考えると, 式(33) は更に 


$$
\log \left(k_{r}{ }^{\prime} / k_{r}\right)=\alpha E(\mathrm{~A})=\log K_{\mathrm{lg} . \mathrm{A}}
$$

と近似できる。すなわち, $\mathrm{Hg}^{2+}$ は $\mathrm{S}_{2} \mathrm{O}_{3}{ }^{2--}$ のような軟ら かい配位子と安定な錯体を生成するので，このような配 位子がAとして共存すると式 (33)の $\log \left(k_{r}{ }^{1} / k_{\mathrm{r}}\right)$ が大き くなり, $\mathrm{A}$ の高感度定量が可能になる。㝳方, $\mathrm{Hg}^{2+}$ は $\mathrm{SO}_{4}{ }^{2-}$ のような硬い配位子とは安定な錯体を生成しない ので，このような配位子が多量に共存しても $\mathrm{S}_{2} \mathrm{O}_{3}{ }^{2-}$ の ような軟らかい配位子の選択定量が可能になる。このよ うな问能性を検討した結果を以下に示す。

\section{$6 \cdot 1$ 配位子置換反応}

式(19)のR及びYに4-(2-ピリジルアゾ)レソルシ） ール (PAR) $\left(\mathrm{H}_{2} \mathrm{R}\right)$ 及び CyDTA $\left(\mathrm{H}_{4} \mathrm{Y}\right)$ を選び

$$
\mathrm{HgR}_{2}{ }^{2-}+\mathrm{HY}^{3-}+\mathrm{H}^{+} \rightarrow \mathrm{HgY}^{2-}+2 \mathrm{HR}^{-}
$$

で表される $\mathrm{pH}=8.9$ での反忘に対する $\mathrm{Cl}^{-}, \mathrm{Br}^{-}, \mathrm{I}^{-}$， $\mathrm{SCN}^{-}, \mathrm{NH}_{3}, \mathrm{NO}_{3}{ }^{-}, \mathrm{SO}_{4}{ }^{2-}, \mathrm{SO}_{3}{ }^{2-}$ 及び $\mathrm{S}_{2} \mathrm{O}_{3}{ }^{2-}$ の効果 を検討した。なお, 反心はホウ酸塩緩衝液で $\mathrm{pH}$ を調節 した $\mathrm{Hg}(\mathrm{II})-\mathrm{PAR}$ 溶液と CyDTA 溶液とを体積比 $1: 1$ で 混合し, $500 \mathrm{~nm}$ での吸光度の経時変化を自動記録して 追跡した. 又, 反応溶液のイオン強度は過塩素酸ナトリ ウムで 1 に調節し，すべての测定は循環恒温水槽及び 恒温七ルホルダーを用い $25^{\circ} \mathrm{C}$ で行った。

$$
C_{\mathrm{Ig}}=1 \times 10^{-5} \mathrm{M}, C_{\mathrm{R}}=8 \times 10^{-4} \mathrm{M} \text { 及び } C_{\mathrm{r}}=1 \times 10^{-4} \mathrm{M}
$$
で

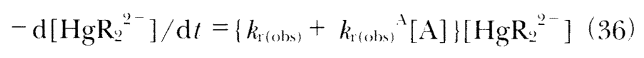

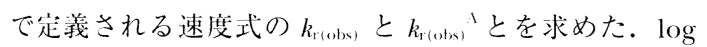
$k_{\text {(lobs) }}{ }^{1}$ と $E(\mathrm{~A})$ とのプロットを Fig. 4 に示す $\left(1 \times 10^{-2}\right.$ $\mathrm{M}$ までの $\mathrm{NO}_{3}{ }^{-}$と $\mathrm{SO}_{4}{ }^{2-}$ は加速効果を示さなかった).

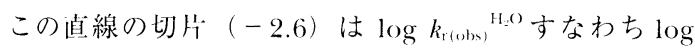
$k_{\text {(olw) }}$ に相当するが, 実測值 $(-2.2)$ と比較的よく一致 している。ところが，傾き（2.9）は式(34)の $\alpha$ 值 (5.8; Table 1 参照) よりかなり小さい.この違いは現 時点では説明できないが, 予想どおり $\mathrm{SO}_{+}{ }^{2-}$ と $\mathrm{SO}_{3}{ }^{2-}$ との間には大きな加速効果の差が認められた。

\section{$6 \cdot 2$ 亜硫酸塩の接触分析}

$C_{\mathrm{Hg}}=1 \times 10^{-5} \mathrm{M}, C_{\mathrm{R}}=8 \times 10^{-4} \mathrm{M}, C_{\mathrm{R}}=1 \times 10^{-4} \mathrm{M}$ 及 び $\mathrm{pH}=8.4$ で $500 \mathrm{~nm}$ での吸光度を約 1 分間測定し, 反応開始 4 秒後と 20 秒後の吸光度差から $\mathrm{SO}_{3}{ }^{2-}$ を定量

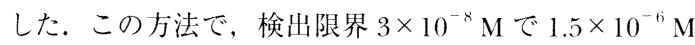

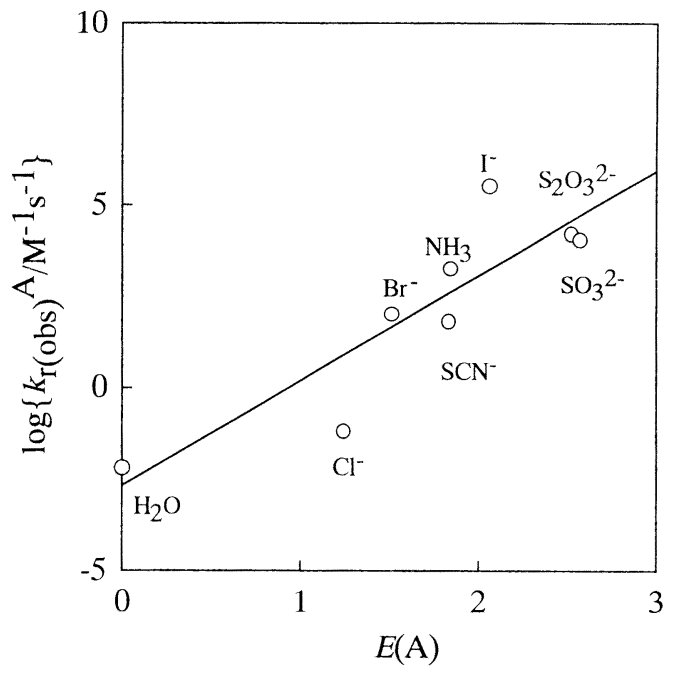

Fig. 4 Plot of $\log k_{r(o b s)}{ }^{1}$ against $E(\mathrm{~A})$

までの $\mathrm{SO}_{3}{ }^{2-}$ が定量でき, $1 \times 10^{-6} \mathrm{M}$ の $\mathrm{SO}_{3}{ }^{2-}$ の嘥星に おいて 10000 倍モルまでの $\mathrm{SO}_{4}{ }^{2-}$ の共存が許容できた。

$\mathrm{SO}_{3}{ }^{2-}$ と同程度の加速効果を示した $\mathrm{S}_{2} \mathrm{O}_{3}{ }^{2-}$ について も $\mathrm{SO}_{3}{ }^{2-}$ と同様に検討した結果，検出限界 $2 \times 10^{-8} \mathrm{M}$ で $7 \times 10^{-7} \mathrm{M}$ までの $\mathrm{S}_{2} \mathrm{O}_{3}{ }^{2-}$ が定量でき， $4 \times 10^{-7} \mathrm{M}$ の $\mathrm{S}_{2} \mathrm{O}_{3}{ }^{2-}$ の定量において 25000 倍モルまでの $\mathrm{SO}_{4}^{2-}$ の其 存が許容できた。

$$
7 \text { 結 } \overline{\overrightarrow{1}}
$$

金属錯体の関与古る反応系での速度差を用いる分析沙 を設計するためには，律速段階前の平衡定数と律速段陛 の速度定数の大きさを支配している要因を理解する必䘫 があるとの観点から，この問題に対する錯形成文心の機 構論的考察からの考え方を示した，是荲的に义㐫性の等 を予測し, 適切に反応系を選択し, 反灾条件を最適化す るためには，まだ解決しなければならない点が幾つか残 されてはいるが，ここで紹介した二，三の応朋例がボす ようにこのような考え方は金属錯体が関与する伈に 基づく速度差分析法を設計開発する際の指針になるもの と考えている.

\section{文献}

1) 中野恵文, 河嶌拓治：ぶんせき (Bunseki), 1987, 317.

2) 田端正明，中野患文，河嶌拓治：ぶんせき (Bunseki), 1988, 347.

3) 阿部重喜, 遠藤昌敏：ぶんせき (Bunseki), 1992 , 623. 
4) 山田畺吉：ぶんせき (Bunseki), 1995, 285.

5) S. Yamada, M. Tanaka: J. Inorg. Nucl. Chem., 37, $587(1975)$

6) S. Yamada, M. Tanaka: J. Chem. Soc., Chem. Commun., 1976, 178.

7) S. Yamada, K. Ohsumi, M. Tanaka: Inorg. Chem., 17, 2790 (1978)

8) S. Yamada, T. Kido, M. Tanaka: Inorg. Chem., 23, 2990 (1984).

9) S. Yamada, A. Iwanaga, S. Funahashi, M. Tanaka: Inorg. Chem., 23, 3528 (1984)

10) S. Yamada, M. Tanaka: Bull. Chem. Soc.Jpn., 58, $2234(1985)$.

11) S. Yamada, I. Yamauchi, A. Murata: Ancl. Sci., 11, 903 (1995).

12) S. Yamada, A. Murata and M. Tanaka: Mikrochim. Acta [Wien], 1988 III, 291.

13) 山田眞吉：ぶんせき (Bunseki), 1989,885.

14) 山田鱼吉, 河窵拓治, 中野恵文: “最新の分離・ 精製・検出法”, 梅澤喜夫，澤田嗣郎，中村 洋監 修, p. 476 (1997), (エヌ・ティー・エス).

15) S. Yamada, H. Anma, A. Murata: Anal. Sci., 4, 49 (1988).

16) S. Yamada, N. Taki, T. Katoh, A. Murata: Anal. Sci., 6, 567 (1990).

17) 山田眞吉, 前島勝已, 村用旭: 分析化学: (Bunseki Kagaku), 40, 455 (1991).

18) 山田眞吉, 高井直人, 中村 基, 中村茂: 分 析化学: (Bunseki Kagaku), 40, 543 (1991).
19) 山田黄占, 大广教義, 中村 基, 中村 茂: 分 析化学 (Bunseki Kagaku), 41, 257 (1992).

20) 山田眞苦, 阿知波信夫, 中村基, 小村茂: 分析化学 (Bunseki Kagaku), 45, 265 (1996).

21) S. Yamada, F. Umika, M. Nakamura, S. Nakamura: Talanta, 43, 1715 (1996).

$22)$ K. B. Yatsimirskii: "Kinetic Methods of Analysis", (1966), (Pergamonn, Oxford).

23) H. B. Mark, Jr., (;. A. Rechnit\%: "Kinetics in Analytical Chemistry", (1968), (Interscience, New York).

24) M. Kopanica, V. Stara: "Kinetic Methods in C:hemical Analysis" in "Comprehensive Analytical Chemistry", vol. 18, Edited by G. Svehla, (1983), (Elsevier, Amsterdanı).

25) H. A. Mottola: "Kinetic Aspects of Analylical Chemistry", (1988), (John-Wilev, New York).

26) M. Tanaka: J. Inorg. Nucl. Chem., 35, 965 (1973); 36, 151 (1974).

27) 清木 晋, 山旦眞南, 中村 基：川本分析化兴会 第 45 年会講演姴旨集, p. 55 (1996).

28) S. Yamada, K. Shibata, A. Murata: Anal. Sci., 9, 467 (1993)

29) 山田眞吉, 森寿美, 中村基, 中村茂：分 析化学: (Bunseki Kagaku), 44, 67 (1995).

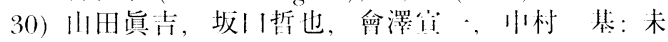
発表.

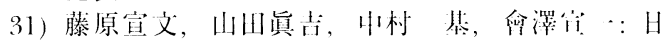
本分析化学会第46 年会溝演装旨集, p. 78 (1997).

\section{要旨}

金属イオン及びその錯体の反心性に関する機構論的考察から，錯形成又灾及び配位了置換义心の速度

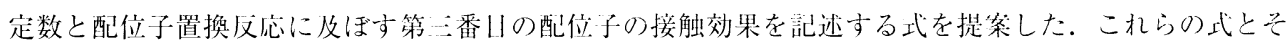
こに含まれるパラメーターを用い，酸化数の晎なる無機化学種の定星のための幾つかの速度算分析を圂

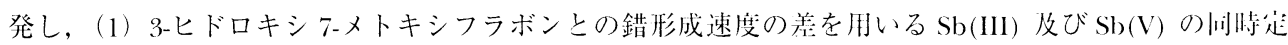

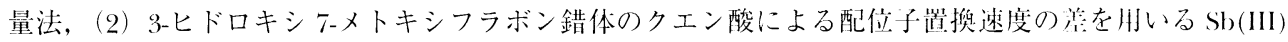
共存下での $\mathrm{Sb}(\mathrm{V})$ の選択定星法，（3）モリンとの錯形成速度の差を用いる $\mathrm{Sn}(\mathrm{II})$ 其你トでの $\operatorname{Sn}(\mathrm{IV})$ の

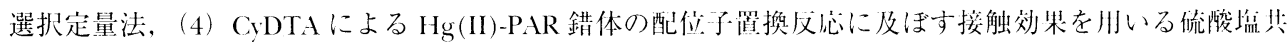
存下でのチ才硫酸塩及び要硫酸塩の選択定量法についての結果を小した。 